\title{
Posterior midline activation during symptom provocation in acute stress disorder: an fMRI study
}

\author{
Jan C. Cwik ${ }^{1,2}{ }^{*}$, Gudrun Sartory ${ }^{1}$, Benjamin Schürholt ${ }^{1}$, Helge Knuppertz ${ }^{1}$ and Rüdiger J. Seitz ${ }^{3}$ \\ ${ }^{1}$ Department of Clinical Psychology and Psychotherapy, University of Wuppertal, Wuppertal, Germany \\ ${ }^{2}$ Mental Health Research and Treatment Center, Department of Clinical Psychology and Psychotherapy, University of Bochum, Bochum, Germany \\ ${ }^{3}$ Department of Neurology, University of Düsseldorf, Düsseldorf, Germany
}

\author{
Edited by: \\ Joaquim Radua, King's College \\ London, UK \\ Reviewed by: \\ Victoria Villalta-Gil, Vanderbilt \\ University, USA \\ Joaquim Radua, King's College \\ London, UK \\ Benedikt L. Amann, Fidmag Research \\ Foundation Hermanas Hospitalarias, \\ Spain \\ *Correspondence: \\ Jan C. Cwik, Mental Health Research \\ and Treatment Center, Department of \\ Clinical Psychology and \\ Psychotherapy, University of Bochum, \\ Massenbergstraße 9-13, Bochum \\ 44787, Germany \\ e-mail:jan.cwik@rub.de
}

\begin{abstract}
Functional imaging studies of patients with post-traumatic stress disorder showed widespread activation of midline cortical areas during symptom provocation, i.e., exposure to trauma-related cues. The present study aimed at investigating neural activation during exposure to trauma-related pictures in patients with acute stress disorder (ASD) shortly after the traumatic event. Nineteen ASD patients and 19 healthy control participants were presented with individualized pictures of the traumatic event and emotionally neutral control pictures during the acquisition of whole-brain data with a 3-T fMRI scanner. Compared to the control group and to control pictures, ASD patients showed significant activation in midline cortical areas in response to trauma-related pictures including precuneus, cuneus, postcentral gyrus, and pre-supplementary motor area. The results suggest that the trauma-related pictures evoke emotionally salient self-referential processing in ASD patients.
\end{abstract}

\section{Keywords: acute stress disorder, trauma, symptom provocation, fMRI, precuneus}

\section{INTRODUCTION}

Acute stress disorder (ASD) is a trauma- and stress-related disorder following a traumatic event. The diagnostic criteria are intrusive re-experiencing of the trauma, autonomic reactivity in response to and avoidance of trauma-related cues, dissociation, mood deterioration, and elevated arousal that last for a minimum of 3 days and at the longest 1 month after the trauma (1). Trauma victims showing similar symptoms 1 month after the traumatic event are given the diagnosis of post-traumatic stress disorder (PTSD). A number of neuroimaging studies and subsequent meta-analyses (2-5) have been carried out on the neuronal circuit underlying PTSD. There is, however, a paucity of studies in ASD.

The key neuronal structures that were proposed to underlie PTSD are a hyperresponsive amygdala and a hyporeactive anterior cingulate cortex (ACC). The amygdala has been shown to be essential for fear conditioning (6) and to exhibit hyperresponsivity to trauma-related cues in PTSD patients [e.g., (7)]. The ACC has been associated with emotional regulation (8) and found to show diminished activity in trauma victims when confronted with trauma-related stimuli [e.g., (9)]. Additionally, a deficient hippocampal function was proposed to prevent the reassessment of the traumatic event [e.g., (10)]. Neuroimaging studies used PET or fMRI to investigate the neuronal response to symptom provocation, i.e., the presentation of trauma reminders such as pictures, sounds, or script-driven imagery of the traumatic event in chronic PTSD patients [e.g., $(7,11,12)]$. Results were, however, only partly convergent and recent meta-analyses revealed additionally activated cortical areas which were not components of the proposed circuit $(4,5)$. The reasons for the inconsistent results are due to a number of reasons such as methodological differences between studies, viz. region-of-interest (ROI) versus whole-brain analysis, but also to the clinical heterogeneity of the PTSD patients (13) and their variable chronic comorbid disorders with a high proportion of the patients suffering from depression and from substance-related disorders.

It is noteworthy that the unique clinical features of PTSD namely, re-experiencing and flashbacks, were not accounted for by the proposed neuronal circuit. The meta-analyses by Hayes et al. (4) and Sartory et al. (5) attempted to address this issue. Hayes et al. (4) analyzed the results of 12 symptom provocation studies and employed activation likelihood estimation, the results of which are based on peak locations of significant activation clusters. Sartory et al. (5) entered 19 neuroimaging studies of symptom provocation in patients and healthy trauma-exposed participants into effect size-signed differential mapping (ES-SDM) (14), a further development that combines peak coordinates and statistical parametric maps, and represents effect-sizes (15). Trauma patients as compared to controls with regard to their response to trauma-related stimuli as well as compared to neutral stimuli revealed increased activation in midline structures including the retrosplenial cortex, precuneus, ACC, in addition to the amygdala. The posterior midline structures have been implicated in self-referential processing and salient autobiographical memory independently of sensory modality (16-21). Moreover, retrosplenial cortex has been shown to be essential for forming associations between multiple sensory stimuli in rodents (22) and for learning contextual associations and priming in humans $(23,24)$. Accordingly, it was hypothesized that the trauma-related stimuli elicited autobiographically 
relevant memories in the trauma patients. This is supported by the finding that priming has an important function with regard to the intrusive re-experiencing of the traumatic event (25).

Compared to the large number of studies in chronic PTSD patients, there are only few in recent trauma victims. Among them is an early PET study of bank officials who had experienced an armed robbery and were shown the security video (26). Compared to a control video, the traumatic stimulation elicited increased activity in visual cortex, posterior gyrus cinguli, and left orbitofrontal cortex, and decreased activity in, among others, Broca's area and angular gyrus. Although the results suggested altered activity in brain regions associated with cognition and affect, in the absence of control participants, it remained unclear whether the trauma victims had merely reacted to the emotional salience of the video or whether self-referential processes were involved. The patients were also not assessed for ASD.

In the study by Osuch et al. (27), the majority of the patients endorsed symptoms in each of the ASD symptom clusters. Motorvehicle collision survivors and non-traumatized controls were exposed to trauma- and neutral-scripts. Unlike controls, ASD participants showed decreased activity in the amygdala and hippocampus and increased activity in medial prefrontal cortex in response to the trauma scripts. Decreased activity of the left amygdala was related to subsequent clinical improvement and the authors concluded that the activation pattern during exposure to trauma reminders underlay adaptive processes. As the authors carried out hypotheses-driven ROI analyses which were confined to amygdalar and frontal brain areas rather than a whole-brain analysis, possible activation in posterior brain regions may have escaped their notice.

So far, it is unclear whether, similar to PTSD patients, ASD patients exhibit activation of posterior midline areas implicated in self-referential processing and salient autobiographical memory. It is conceivable that the latter are the result of long-term consolidation of the trauma memory and that ASD is characterized by a frontal network, i.e., a hyperactive amygdala and hyporeactive ACC.

In the present study, personalized trauma-related pictures were used as in previous studies in PTSD patients $(9,11,28-31)$. Similar to specific phobics [e.g., (32)] and unlike controls, ASD patients were found to show heart-rate acceleration to personalized trauma pictures (33) indicative of a fear response. The extent of the heart-rate acceleration was also found to be related to severity of intrusions and the risk of developing PTSD in ASD patients (34).

The aim of the present study was to investigate the neural basis of symptom provocation in ASD patients. Patients with a confirmed diagnosis of ASD and healthy control participants took part. Whole-brain analyses were carried out. We expected trauma victims to show increased activation in amygdala and decreased activation of medial prefrontal areas.

\section{MATERIALS AND METHODS \\ PARTICIPANTS}

Nineteen participants with ASD [15 F, 4 M; mean age 35.5 years $(\mathrm{SD}=13.7)]$ and 19 healthy control participants who had not experienced a traumatic event [10 F, 9 M; mean age 29.6 years $(\mathrm{SD}=12.0)]$ took part in the study. All participants were right-handed according to the Edinburgh Handedness Inventory (35). Another 10 trauma victims were excluded because of premature termination of the scanning procedure (3), metallic implants (2), medication (2), equipment malfunction (2), and exaggerated movement (1). The traumatic event had occurred on average 16.95 days $(S D=6.55$; range $9-31$ days $)$ prior to the fMRI procedure. Participants were recruited via the local police department and accident and emergency departments of hospitals, among other sources. The following traumatic incidences were reported: break-in/robbery (11), traffic accident (5), and violent threat/assault (3). Comorbid disorders among ASD participants at the time of assessment were: depression (4), panic disorder/agoraphobia (3), specific phobia (1), general anxiety disorder (1), and dysthymia (1). Control participants underwent a clinical assessment and the presence of a disorder was an exclusion criterion in this group. The study was approved by the Ethics Committees of the Universities of Wuppertal and Düsseldorf. All participants gave their written informed consent before entering the study and received a small remuneration to cover travel expenses. After the study, trauma-focused cognitive behavior therapy was offered to all patients.

\section{STIMULI}

At the first telephone contact, ASD participants were asked to describe the images occurring to them during intrusions. Based on this information, a set of 20 personalized trauma-relevant and 20 emotionally neutral pictures matched in color and general content (e.g., faces) were chosen for the experiment. Pictures were taken from the international affective picture system (IAPS) (36), the internet or, if available, from press or police reports covering the event. ASD participants were asked to rate the 40 pictures according to how much they reminded them of the trauma and how much fear they induced, each on a five-point scale (SuperLab Version 2.0; Cedrus Corporation, CA, USA) (see Figures 1A,B). Fifteen trauma pictures with the highest and 15 of the neutral pictures with the lowest rating of trauma relevance were chosen as stimulus material for the respective ASD participant. Each control participant was matched with one of the ASD patients with regard to the presented pictures. Additionally, scrambled versions of the pictures were produced by adjusting them to $600 \times 800$ pixels and scrambling them into squares of $10 \times 10$ pixels (see Figure 1C). In the scanner, pictures were presented for 3-5 s, followed by the respective scrambled version for 11-13 s (Figure 1C).

\section{IMAGING METHOD}

MRI data scanning was performed at the Department of Neurology, University of Düsseldorf, on a Siemens Magnetom TRIO 3-T MRI scanner. Echoplanar $T_{2}^{*}$-weighted imaging (EPI) was obtained whole-brain in 136 images with 44 slices [repetition time (TR) $4 \mathrm{~s}$, echo time (TE) $40 \mathrm{~ms}$, flip angle $90^{\circ}$, matrix $128 \times 128$, field of view (FOV) $192 \mathrm{~mm} \times 192 \mathrm{~mm}$, pixel size $1.5 \mathrm{~mm} \times 1.5 \mathrm{~mm}, 3 \mathrm{~mm}$ slice thickness, interleaved-even). No pictures were presented during the acquisition of three initial "dummy" volumes. High-resolution $T_{1}$-weighted structural images were acquired for each participant using a magnetizationprepared gradient echo sequence in 192 slices with a voxel size of $1 \mathrm{~mm} \times 1 \mathrm{~mm} \times 1 \mathrm{~mm}\left(\mathrm{TR}=2.3 \mathrm{~s}, \mathrm{TE}=2.98 \mathrm{~ms}\right.$, flip angle $=90^{\circ}$, 

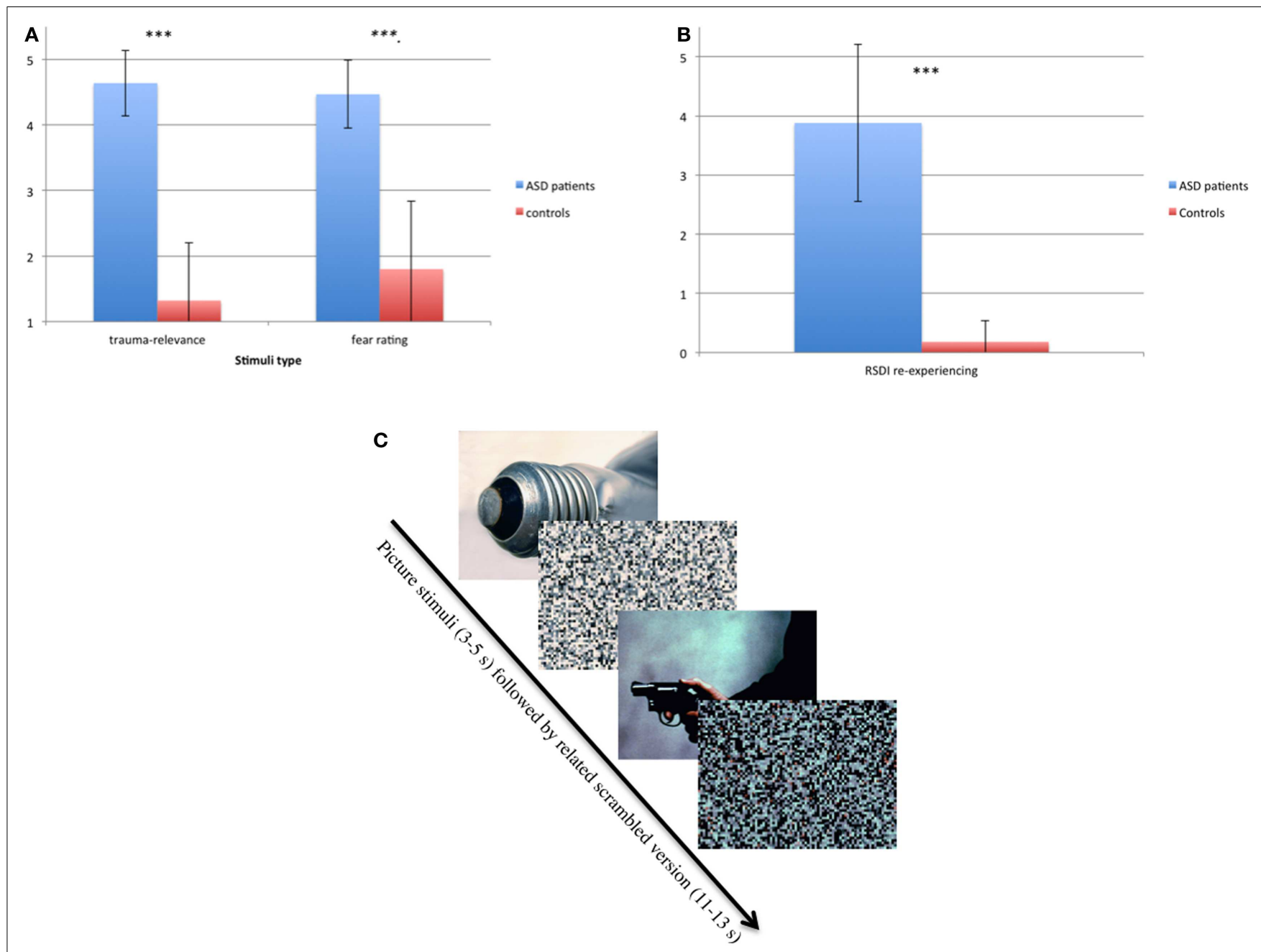

FIGURE 1 | (A) Ratings of trauma relevance (1-5) and fear-inducing ratings (1-5) of trauma-relevant pictures in ASD and control participants. ${ }^{* *} p<0.001$ (B) Ratings of re-experiencing measured with RSDI (0-6) in ASD and control participants immediately after the symptom provocation procedure in the scanner. ${ }^{* *} p<0.001$. (C) Example of the two types of pictures (neutral and trauma-related) taken from IAPS (36) and their scrambled version.
FOV $=256 \mathrm{~mm} \times 256 \mathrm{~mm}$, matrix $=256 \times 256)$ for localization and coregistration of the functional data. Stimuli onsets were recorded using RTEwin (RTEwin ${ }^{\circledR}$ software; Version 1.81, MH GmbH, Erftstadt $)^{1}$.

Image processing and statistical analysis were performed with Statistical Parametric Mapping (SPM8, Wellcome Department of Neurology, London, UK) $)^{2}$. Data were realigned and unwarped (using fourth degree B-Spline and motion parameters) and slice time corrected. After coregistration to the structural images, EPI images were spatially normalized to Montreal Neurological Institute $(\mathrm{MNI})$ standard space with a voxel size of $3 \mathrm{~mm} \times 3 \mathrm{~mm} \times 3 \mathrm{~mm}$ and smoothed with a 9-mm full-width-athalf-maximum (FWHM) Gaussian kernel. A high-pass filtering with a cut-off at $128 \mathrm{~s}$ was used to minimize the impact of serial autocorrelations in the fMRI time series. Parameter estimation was

${ }^{1}$ http://www.mh-gmbh.de/

${ }^{2}$ www.fil.ion.ucl.ac.uk/spm/ corrected for temporal autocorrelations using a first-order autoregressive model and motion. Using convolving stick functions with the canonical hemodynamic response function (HRF), and parameter estimates pertaining to the amplitude of the HRF, each experimental condition ( trauma $>$ neutral, neutral $>$ trauma) was calculated. As recommended by Francati et al. (37), neutral pictures were used as intrapersonal and healthy control group as interpersonal baseline.

\section{CLINICAL MEASURES AND QUESTIONNAIRES}

Acute Stress Disorder Interview [ASDI; (38); German translation: (39)] was used to assess diagnostic ASD criteria. Anxiety Disorder Interview Schedule [ADIS-IV; (40); German version: Mini-DIPS; (41)] was given to both groups. In addition to assessing diagnostic criteria of anxiety, affective, and somatoform disorders, there are also screening questions as to psychotic and substance-related disorders in the German version of the ADIS. Impact of Event Scale [IES-R; (42); German version: (43)]: this self-rated questionnaire 
assesses trauma severity in terms of avoidance, intrusiveness, and hyperarousal. Beck Depression Inventory [BDI-II; (44); German version: (45)] and the State-Trait Anxiety Inventory [STAI; (46); German version, (47)] were used for the assessment of depression and anxiety, respectively. Responses to Script-Driven Imagery Scale [RSDI; (48); German version: (49)] is a brief self-report scale of PTSD symptoms evoked by imagery during the presentation of the trauma script. For the present study, RSDI was adjusted to symptom provocation by trauma-relevant pictures. Immediately after the scanning procedure, participants were asked to rate the extent to which re-experiencing, avoidance, and dissociation symptoms had occurred on a scale from " $0=$ not at all" to " $6=$ very intense."

\section{PROCEDURE}

Acute stress disorder participants were informed about the trauma study by the cooperating institutions. Either participants themselves or the institutions established contact. In the first telephone contact, participants were asked about the images occurring to them during intrusions. Based on the participants' report, the set of 40 pictures was chosen. Within 1 week after the telephone contact, participants underwent the assessment (clinical structured interviews and questionnaires) and rated the picture set. According to this rating, the final 30 pictures were selected such that the pictures were the most trauma-relevant for each trauma subject. Another week later, the fMRI scan was carried out. Participants were in supine position in the scanner while the 30 pictures were shown in pseudo-randomized order (Presentation ${ }^{\circledR}$ software; Version 14.9$)^{3}$, i.e., the same order of trauma-relevant and neutral pictures was maintained and was presented to the ASD and control participants. Each picture was projected onto a mirror mounted on the head-coil above the participant's head. Participants were instructed not to move and to view all pictures attentively. A passive viewing task was chosen to ensure that the resulting neural activation pattern is similar to that of intrusions which are thought to occur during passive confrontation with trauma-related cues. Participants were given a button to press in case of indisposition in the scanner. Immediately after the scan, participants were asked to fill in the RSDI.

\section{STATISTICAL ANALYSIS}

Hypotheses were tested as planned contrasts in a random-effects model in which linear combinations of model parameters were evaluated using $t$-statistics, focusing on comparisons between traumatic versus neutral pictures. Linear contrasts were carried out to test within- and between-group differences with regard to location and intensity of the BOLD response during the picture presentation, relative to the baseline BOLD response. Functional maps of the activated voxels were constructed by comparing the signal intensity observed during the picture presentation relative to the scrambled version for each participant on a voxel-by-voxel basis. To balance the risk of Type I and Type II errors, significant clusters had to have (a) $k>=15$ voxels; (b) $p$-value $<0.05$ (FWEcorrected) in between-group comparisons and a $p$-value $<0.01$ (FWE-corrected) in within-group comparisons; and (c) one or more voxels with FDR $<0.01$.

\footnotetext{
${ }^{3}$ www.neurobs.com
}

The loci of observed responses were characterized by the voxel exhibiting the maximum effect size within each cluster in terms of the MNI coordinate system. The WFU Pickatlas (Version 3.0.4, Wake Forest University, School of Medicine, NC, USA) was used to localize clusters and determine average $t$-values of clusters. Within each group, a fixed-effects model was generated to examine differences between trauma and neutral pictures.

Clinical data were compared between groups using two-tailed $t$-tests. Correlation analyses were conducted to test associations of the participants' years of education with the eigenvariate of each significant cluster of the between-group comparison as well as the within-group comparison. The statistical modeling and analysis was carried out using R for Mac OSX [Version 3.0.1; (50)]. The statistical threshold of significance for results was set at $p<0.05$.

\section{RESULTS}

\section{DEMOGRAPHIC AND CLINICAL VARIABLES}

Demographic and clinical data are displayed in Table 1. Patients had an age range of $20-63$ and controls of $19-58$ years. There was no group difference with regard to age but to years of education and clinical variables (Table 1). The correlation analyses between years of education and the eigenvariate of each significant cluster of the between-group comparison as well as the within-group comparison showed no significant results (between $r=0.077, p=0.755$ and $r=0.183, p=0.454)$. ASD patients rated the trauma-related pictures as reminding them strongly of their trauma and being more fear-inducing $(p<0.001)$ than the controls. The RSDI ratings revealed that the procedure evoked ASD symptoms in patients. In contrast, there were no group differences with regard to the neutral pictures.

\section{fMRI}

\section{Group differences}

Table 2 shows the significantly greater activations in the ASD subjects as compared to the control subjects for the trauma-specific fMRI signal changes. Significant major clusters were observed close to the midline in left precuneus and cuneus $(\mathrm{BA}=7,19)$ as well as right superior frontal gyrus $(B A=6)$ and the cerebellar declive. No regions of significant hypoactivation were found (Figure 2).

\section{ASD patients: trauma-related versus neutral pictures}

Significant activations were observed in the left precuneus $(\mathrm{BA}=7)$ and posterior cingulate cortex $(\mathrm{BA}=31)$ and the right superior frontal gyrus $(\mathrm{BA}=6)$ (Table 3). Additionally, there were large activated areas bilaterally in the right inferior frontal gyrus $(\mathrm{BA}=47)$ extending into the adjacent superior temporal gyrus as well as in the right cerebellar declive (Figure 3 ). No regions of significant hypoactivation were found.

\section{Controls: trauma-related versus neutral pictures}

Control participants showed activated areas in the right inferior frontal and superior temporal gyrus as well as in the left superior frontal gyrus in response to trauma-related compared to neutral pictures (Table 4; Figure 4).

\section{DISCUSSION}

Acute stress disorder patients rated the trauma-relevant pictures as being strongly reminiscent of their traumatic event and reported 
Table 1 | Demographic and clinical characteristics of patients with acute stress disorder (ASD) and controls.

\begin{tabular}{|c|c|c|c|c|c|c|}
\hline & \multicolumn{2}{|c|}{$\begin{array}{c}\text { ASD } \\
N=19\end{array}$} & \multicolumn{2}{|c|}{$\begin{array}{l}\text { Controls } \\
\qquad N=19\end{array}$} & $t$-Test $/ \chi^{2}$-test statistics & $p$-Value \\
\hline Age (years) & 35.47 & 13.67 & 29.63 & 11.98 & $t(36)=1.40$ & 0.170 \\
\hline Sex, F/M & $15 / 4$ & & $10 / 9$ & & $\chi^{2}(1, N=38)=2.92$ & 0.087 \\
\hline BDI-II (0-63) & 19.32 & 13.58 & 2.63 & 2.91 & $t(36)=5.237$ & $<0.001 * * *$ \\
\hline IES-R intrusion (0-35) & 25.42 & 8.44 & - & & & \\
\hline IES-R avoidance (0-40) & 22.74 & 12.11 & - & & & \\
\hline IES-R hyperarousal (0-35) & 24.68 & 8.39 & - & & & \\
\hline STAI-state $(20-80)$ & 48.32 & 9.59 & 30.74 & 3.03 & $t(36)=7.62$ & $<0.001^{* * *}$ \\
\hline Fear rating $(1-5)$ & 4.47 & 0.52 & 1.80 & 1.04 & $t(36)=10.06$ & $<0.001 * * *$ \\
\hline \multicolumn{7}{|l|}{ NEUTRAL PICTURES } \\
\hline Relevance rating (1-5) & 1.05 & 0.15 & 1.00 & 0.00 & $t(36)=1.46$ & 0.154 \\
\hline Fear rating $(1-5)$ & 1.06 & 0.11 & 1.06 & 0.15 & $t(36)=0.01$ & 0.994 \\
\hline RSDI re-experiencing (0-6) & 3.88 & 1.33 & 0.18 & 0.36 & $t(36)=11.70$ & $<0.001 * * *$ \\
\hline RSDI avoidance (0-6) & 2.95 & 1.86 & 0.02 & 0.08 & $t(36)=6.87$ & $<0.001 * * *$ \\
\hline RSDI dissociation (0-6) & 2.50 & 1.92 & 0.01 & 0.06 & $t(36)=5.64$ & $<0.001 * * *$ \\
\hline
\end{tabular}

ASDI, Acute Stress Disorder Interview; BDI-II, Beck Depression Inventory (revised); IES-R, Impact of Event Scale (revised); STAI, State-Trait Anxiety Inventory; RSDI, Response to Script-Driven Imagery Scale. ${ }^{*} p<0.05$; ${ }^{* *} p<0.001$.

Table 2 | Comparison between ASD patients and controls with regard to their response to trauma-related compared to neutral pictures.

ASD patients $>$ controls (trauma-related $>$ neutral pictures)

\begin{tabular}{|c|c|c|c|c|c|c|c|c|c|c|c|}
\hline \multicolumn{2}{|r|}{ Cluster-level } & \multicolumn{6}{|c|}{ Cluster breakdown } & \multicolumn{4}{|c|}{ Peak-level } \\
\hline$k_{\mathrm{E}}$ & $\begin{array}{l}\text { Mean } t \text {-value } \\
\left.\text { (SD; } p_{\mathrm{FWE}}\right)\end{array}$ & Label & $\boldsymbol{k}_{\mathrm{E}}$ & $\begin{array}{l}\text { Mean } \\
t \text {-value (SD) }\end{array}$ & BA & $k_{\mathrm{E}}$ & $\begin{array}{l}\text { Mean } \\
t \text {-value (SD) }\end{array}$ & & $\begin{array}{l}\text { ak MN } \\
\text { ordina }\end{array}$ & & $t\left(p_{\mathrm{FDR}}\right)$ \\
\hline \multirow[t]{3}{*}{367} & $4.26(0.66 ; 0.000)$ & Precuneus & 218 & $4.26(0.65)$ & 7 & 149 & $4.26(0.67)$ & -6 & -76 & 52 & $6.42(0.002)$ \\
\hline & & Cuneus & 29 & $3.80(0.31)$ & 19 & 22 & $3.88(0.27)$ & & & & \\
\hline & & Postcentral G. & 22 & $3.81(0.33)$ & & & & & & & \\
\hline 75 & $3.84(0.38 ; 0.039)$ & Declive & 25 & $3.75(0.36)$ & 18 & 12 & $3.69(0.26)$ & 3 & -82 & -17 & $4.66(0.007)$ \\
\hline
\end{tabular}

All activations are significant whole-brain-analysis effects at $p<0.05$, FWE-corrected on cluster-level, $p<0.01$, FDR-corrected (voxel-wise) on peak-level and a minimum of $k=15$ contiguous voxels $\left(135 \mathrm{~mm}^{3}\right)$. Areas in bold letters refer to the coordinates of the peak-level voxels.

$k_{E}$, number of voxels; BA, Brodmann-area; (pre-)SMA, (pre-)supplementary motor area; G., gyrus.

considerable more symptoms than the control participants during the procedure. However, the results of the study did not confirm the initial hypothesis of a hyperactive amygdala and hyporesponsive ACC. Instead, the ASD patients showed greater activation of midline posterior cortex including precuneus, cuneus, and posterior cingulate cortex together with greater activation in dorsal superior cortex and declive of the cerebellum. Both groups showed increased activation of inferior and medial frontal gyrus as well as superior temporal gyrus and insula in response to trauma-related as compared to control pictures. Only controls showed significant activation in left superior frontal gyrus $(B A=9,10)$. ASD patients thus showed a similar pattern of activation as PTSD patients (5) with regard to posterior midline cortex.

Research in healthy samples has repeatedly shown precuneus to be a core structure of networks underlying autobiographic meaning and emotional salience processing (51-57). For instance, Lee et al. (55) observed higher neural activation in precuneus during recollection of prior negative affective events. Levine et al. (58) 

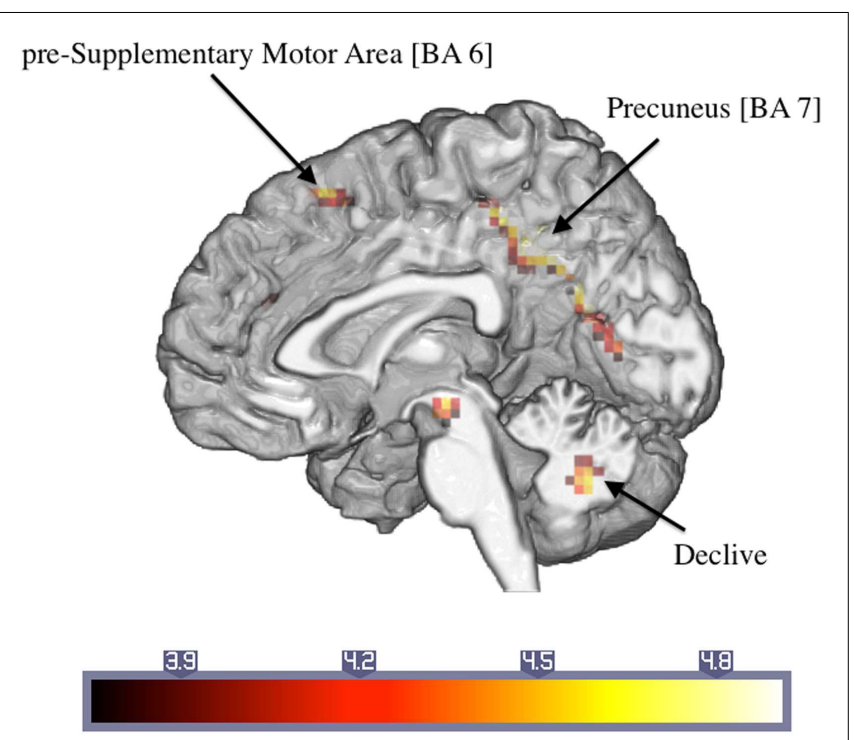

FIGURE 2 | Significantly activated areas in ASD patients compared to controls with regard to the response to the trauma-related versus neutral pictures (number in brackets indicate Brodmann areas).

found episodic autobiographical remembering compared to personal semantic, general episodic memory, or semantic knowledge to elicit increased neural activation in posterior midline cortex including precuneus. Bluhm et al. (59) compared a self-referential processing condition with a general facts condition with the former showing greater neuronal responses at midline precuneus in both healthy participants and PTSD patients. Finally, Sajonz et al. (56) reported an increased BOLD response in this area to self-referential pictures. Reviewing the literature, Cavanna and Trimble (60) concluded that precuneus was involved in diverse functions among them, visual-spatial imagery, episodic memory retrieval, and self-processing operations such as first-person perspective-taking.

In the present study, the large activated cluster containing precuneus also comprised cuneus, area 31 of retrosplenial cortex and the medial aspect of the superior parietal lobule. Underscoring the integrative function of precuneus, connectivity studies revealed this area to be part of a network linking it to cuneus, lingual gyrus, middle frontal gyrus, and supplementary motor area $(53,55,61)$ as well as sensorimotor areas and cerebellum in healthy (62) and traumatized samples (4). This network has been shown to be activated specifically during the recollection of autobiographical memory. For instance, Addis et al. (51) found specific autobiographic memory retrieval to be associated with increased activation of left precuneus, left superior parietal lobule, and right cuneus whereas general memory retrieval was associated with activation of the right inferior temporal gyrus, right medial frontal cortex, and left thalamus. Thus, based on these findings of the functional significance of the activation of posterior midline cortex in healthy samples, the present results may suggest that compared to controls, ASD patients showed greater self-involvement and autobiographical memory retrieval during the presentation of the trauma-related pictures. This conclusion is also confirmed by the relevance ratings given to the trauma-related pictures by ASD patients and their extent of symptom provocation during the scanning procedure but will need to be confirmed by direct measurement of the conjectured process.

Posterior cingulate gyrus together with a large network of other areas has also been identified as the default mode network activated during resting state (57). Lanius et al. (63) showed that increased connectivity with the right amygdala was predictive of PTSD symptoms 3 months post-trauma. Based on these findings, Daniels et al. $(64,65)$ proposed long-term structural changes to the default mode network in PTSD which would in turn incur deficits in cognitive function (57). The latter have, however, not been convincingly demonstrated in ASD or PTSD [e.g., (66)].

Compared to neutral pictures and control participants, ASD patients showed increased activation in midline right superior frontal gyrus comprising the pre-supplementary motor area and the adjacent supplementary motor area (pre-SMA/SMA, BA =6) to trauma-related pictures. In line with studies of motor imagery (67-69), SMA has been found to be functionally connected to precuneus $(53,61,70,71)$, whereas pre-SMA is connected to dorsolateral prefrontal cortex (72). In addition to the well-known executive motor aspects (73), SMA was shown to be involved in sensory and working memory processes in healthy and traumatized participants (74-78) as well as motor inhibition (7982). Pissiota et al. (83) observed increased neural activation in SMA during symptom provocation in a traumatized sample and suggested that this activation pattern represented a functional network supporting emotionally determined motor preparation. Alternatively, it may contain motor aspects of the memory necessary for the preparation of fight or flight. In their meta-analysis of neural activation during symptom provocation in PTSD, Hayes et al. (4) also reported significantly increased activation in SMA during unpleasant stimuli and concluded that its function was preparation to respond. Pre-SMA was found to be involved in the selection and preparation of motion $(82,84-86)$ but also, as shown in a meta-analysis of empathic processing, in the self-referencing of action (87). The increased pre-SMA/SMA activation of ASD patients in the present study could therefore be the result of reexperiencing motion or the preparation of a motor reaction to the trauma-related pictures.

Activation of cerebellum has also been reported previously in the context of emotional processing. In a meta-analysis of imaging studies of emotional face processing, Fusar-Poli et al. (88) found neural activation in cerebellum across all emotional conditions. The researchers interpreted the finding in terms of the arousal-related connection of cerebellum with the reticular system and with cortical association areas subserving cognitive processing of emotions. Driessen et al. (89) also found cerebellar activation during confrontation with traumatic versus unpleasant but non-traumatic key words while Osuch et al. (90) reported increased regional blood flow in cerebellar regions to be positively correlated with flashback intensity in PTSD. Presenting trauma-related pictures to earthquake victims, Yang et al. (30) found bilaterally increased activation in visual association cortex $(\mathrm{BA}=18)$ and cerebellum. Along with other regions associated with autobiographic memory, cerebellum could be involved in visual re-experiencing of emotionally arousing pictures. 
Table 3 | ASD patients: comparison of neural activation to trauma-related as compared to neutral pictures.

ASD patients: trauma-related $>$ neutral pictures

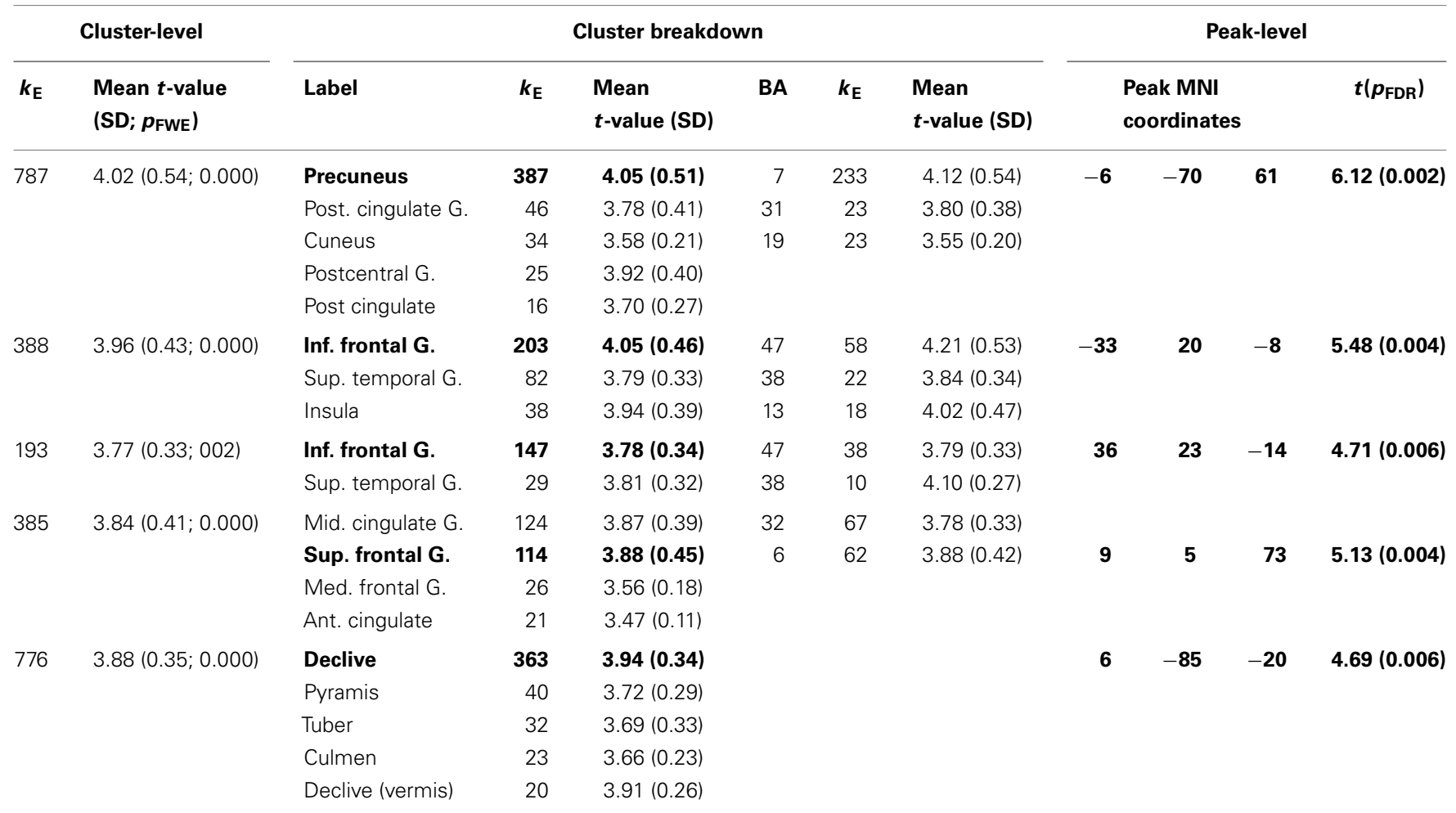

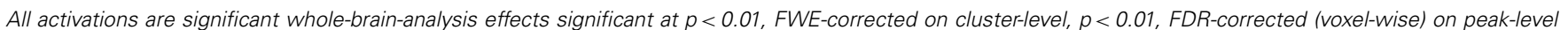
and a minimum of $k=15$ contiguous voxels $\left(135 \mathrm{~mm}^{3}\right)$. Areas in bold letters refer to the coordinates of the peak-level voxels.

$k_{E}$, number of voxels; BA, Brodmann-area; Sup., superior; Mid., middle; Med., medial; Inf., inferior; Post, posterior; Ant., anterior; G., gyrus; L., lobule.

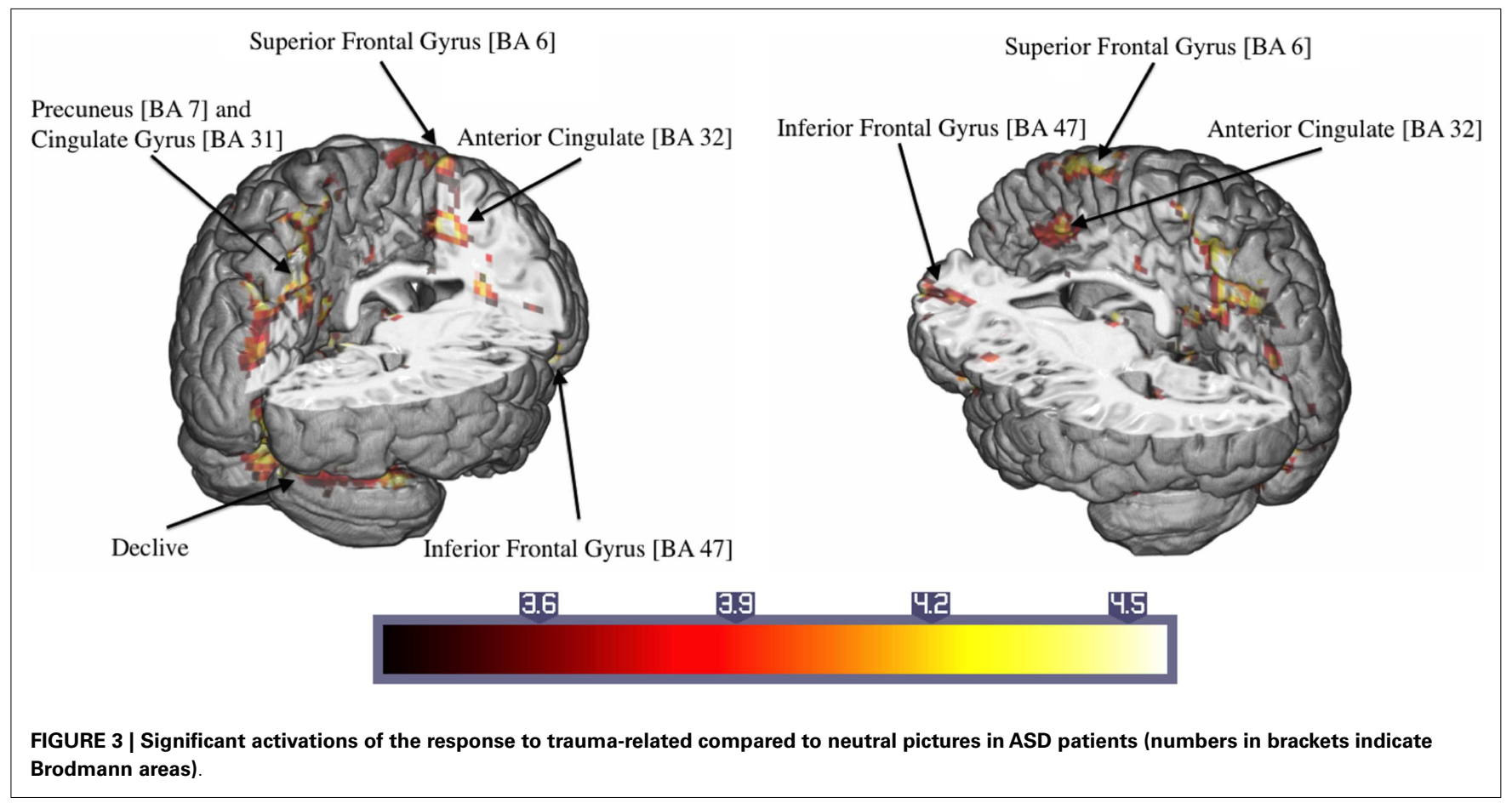


Table 4 | Control participants: comparison of response to trauma-related compared to neutral pictures

Controls: trauma-related $>$ neutral pictures

\begin{tabular}{|c|c|c|c|c|c|c|c|c|c|c|c|}
\hline \multicolumn{2}{|r|}{ Cluster-level } & \multicolumn{6}{|c|}{ Cluster breakdown } & \multicolumn{4}{|c|}{ Peak-level } \\
\hline $\boldsymbol{k}_{\mathrm{E}}$ & $\begin{array}{l}\text { Mean } t \text {-value } \\
\left(\mathrm{SD} ; p_{\mathrm{FWE}}\right)\end{array}$ & Label & $k_{\mathrm{E}}$ & $\begin{array}{l}\text { Mean } \\
t \text {-value (SD) }\end{array}$ & BA & $k_{\mathrm{E}}$ & $\begin{array}{l}\text { Mean } \\
t \text {-value (SD) }\end{array}$ & & $\begin{array}{l}\text { k MNI } \\
\text { rdinat }\end{array}$ & & $t\left(p_{\mathrm{FDR}}\right)$ \\
\hline \multirow[t]{3}{*}{372} & $4.40(0.77 ; 0.000)$ & Inf. frontal G. & 289 & $4.43(0.74)$ & 47 & 52 & $4.36(0.67)$ & 30 & 11 & -11 & $7.23(0.000)$ \\
\hline & & Insula & 17 & $4.75(0.92)$ & 13 & 17 & $4.75(0.92)$ & & & & \\
\hline & & & & & 45 & 16 & $4.31(0.76)$ & & & & \\
\hline & & & & & 10 & 24 & $3.82(0.30)$ & & & & \\
\hline \multirow[t]{3}{*}{106} & $3.77(0.28 ; 0.007)$ & Sup. temporal G. & 49 & $3.82(0.29)$ & 39 & 11 & $3.60(0.14)$ & 45 & -49 & 22 & $4.54(0.008)$ \\
\hline & & Inf. parietal L. & 28 & $3.87(0.29)$ & & & & & & & \\
\hline & & Supramarginal G. & 16 & $3.59(0.15)$ & & & & & & & \\
\hline
\end{tabular}

All activations are whole-brain-analysis effects significant at $p<0.01$, FWE-corrected on cluster-level, $p<0.01$, FDR-corrected (voxel-wise) on peak-level and a minimum of $k=15$ contiguous voxels $\left(135 \mathrm{~mm}^{3}\right)$. Areas in bold letters refer to the peak-level voxels.

$k_{E}$, number of voxels; BA, Brodmann-area; Sup., superior; Inf., inferior; G., gyrus; L., lobule.

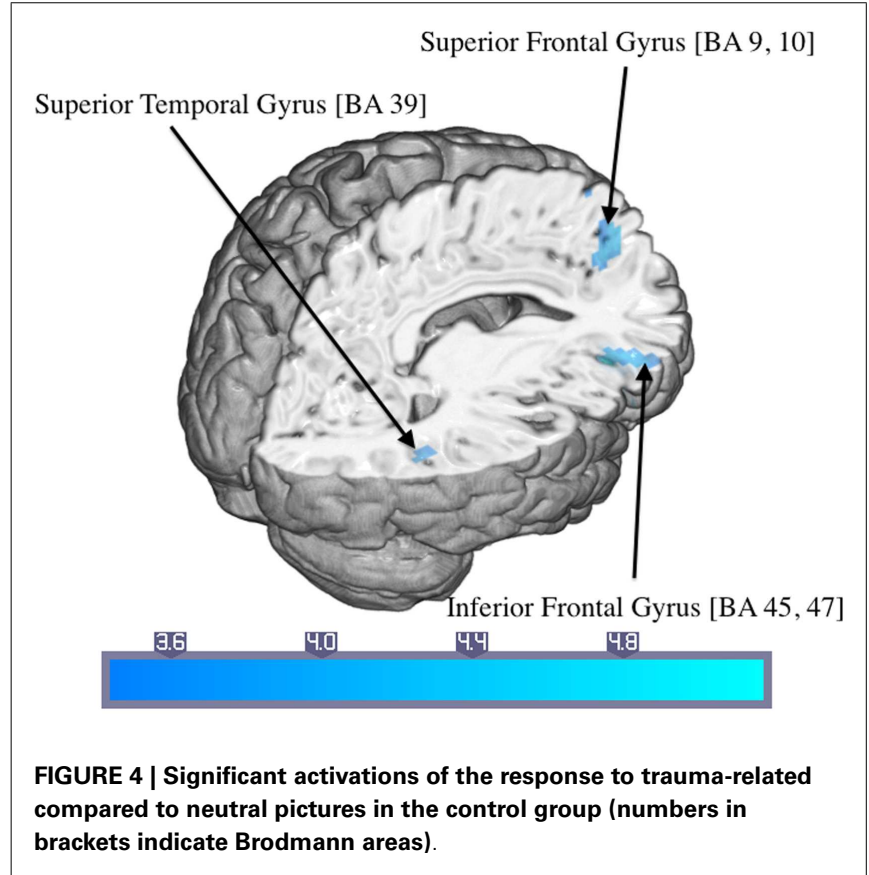

Activation of right inferior frontal gyrus as well as superior temporal gyrus and insula was observed to trauma-related pictures in both ASD patients and controls. Previous studies reported increased activation of inferior frontal cortex to be related to attention (91) and working memory $(92,93)$. Activation of insular cortex has been found to be associated with negative emotions, e.g., disgust $(94,95)$ and other negatively valenced reactions (9698). The observed activation pattern could therefore be seen as a result of negative emotions such as disgust to the trauma-related pictures in both groups.

Comparing the results of the meta-analysis by Sartory et al. (5) of symptom provocation in chronic PTSD to those of the present
ASD patients shows increased neural activation in precuneus in both groups and, to a lesser degree in ASD patients, retrosplenial cortex suggesting that the trauma-related pictures are associated with emotional autobiographical meaning. However, the present ASD group also showed activation of pre-SMA and cerebellar areas not evident in the chronic PTSD patients. Furthermore, the control group of the meta-analysis showed increased activation of sensory associative areas in response to the trauma-related cues which was not the case in the present control group. One of the reasons for this discrepancy could be due to controls having undergone the traumatic event without developing PTSD in the meta-analysis whereas they had not undergone such an event in the present study. Further inconsistencies among results were the increased activation of amygdala and gyrus angularis in PTSD patients not found in the present ASD patients. The discrepancy could be due to the difference in sample size between the meta-analysis and the present study or that a significant BOLD response in amygdala was only found in ROI analyses rather than the present whole-brain analysis. A direct comparison between ASD and PTSD patients would permit drawing firmer conclusions as to the activation of brain areas during the development of the disorder.

Among the limitations of this study is the lack of an additional control group that has undergone a traumatic event without subsequent ASD symptoms. Some of the emotionally driven attentional responses may be accounted for by having recently experienced a respective event. Furthermore, we compared the neural activation of ASD patients with the neural activation of control participants during the presentation of a picture set that was trauma-relevant and therefore emotionally meaningful for the ASD patient but not for controls. Future studies should include emotionally relevant pictures for controls, e.g., of life-event stress for the comparison with trauma-relevant pictures of ASD patients. Francati et al. (37) proposed including healthy or trauma-exposed controls as an interpersonal baseline in neuroimaging studies in addition to neutral stimuli as an intrapersonal baseline. We decided to include healthy controls because it appeared to be the first step in assessing 
characteristics of the disorder. It is, in any case, noteworthy that the present neuroimaging results are similar to those of the previous meta-analysis of PTSD patients compared to trauma-exposed controls (5).

Even though the number of 19 participants in each group approaches the recommended sample size for fMRI studies (99), a larger sample size would have increased the power of the statistical analyses. Furthermore, the incorporation of autonomic measures such as heart-rate would be useful to confirm the distressing quality of the trauma pictures in ASD patients. In addition, future studies could also include negatively valenced pictures to assess whether or not trauma patients respond generally more strongly to unpleasant stimuli or whether their reactivity is confined to personalized trauma reminders. Also of interest could be the comparison of trauma-related pictures with script-driven imagery of the trauma to investigate whether these symptom provocation methods bring about a different neural activation pattern (e.g., posterior versus limbic activation).

Finally, ASD patients of the present study showed a lower educational level than controls which is a frequently reported result in PTSD research (100). Although there was no significant correlation between neural activation and educational level in the present study, the latter is likely to have an impact particularly if cognitive tasks are involved.

\section{ACKNOWLEDGMENTS}

The study was supported by the Deutsche Forschungsgemeinschaft (DFG) (SA 735/18-1; SE 494/7-1). Jan C. Cwik received a postgraduate grant from the University of Wuppertal while completing the study which is a part requirement of his Ph.D.

\section{REFERENCES}

1. American Psychiatric Association. Diagnostic and Statistical Manual of Mental Disorders. 5th ed. Washington, DC: American Psychiatric Association (2013).

2. Etkin A, Wager T. Functional neuroimaging of anxiety: a meta-analysis of emotional processing in PTSD, social anxiety disorder, and specific phobia. Am J Psychiatry (2007) 164:1476-88. doi:10.1176/appi.ajp.2007.07030504

3. Patel R, Spreng RN, Shin LN, Girad TA. Neurocircuitry models of posttraumatic stress disorder and beyond: a meta-analysis of functional neuroimaging studies. Neurosci Biobehav Rev (2011) 36:2130-42. doi:10.1016/j.neubiorev. 2012.06.003

4. Hayes JP, Hayes SM, Mikedis AM. Quantitative meta-analysis of neural activity in posttraumatic stress disorder. Biol Mood Anxiety Disord (2012) 2:9. doi:10.1186/2045-5380-2-9

5. Sartory G, Cwik J, Knuppertz H, Schürholt B, Lebens M, Seitz RJ, et al. In search of the trauma memory: a meta-analysis of functional neuroimaging studies of symptom provocation in posttraumatic stress disorder (PTSD). PLoS One (2013) 8(3):e58150. doi:10.1371/journal.pone.0058150

6. LeDoux JE. Emotion circuits in the brain. Annu Rev Neurosci (2000) 23:155-84. doi:10.1146/annurev.neuro.23.1.155

7. Shin LM, Orr SP, Carson MA, Rauch SL, Macklin ML, Lasko NB, et al. Regional cerebral blood flow in the amygdala and medial prefrontal cortex during traumatic imagery in male and female Vietnam veterans with PTSD. Arch Gen Psychiatry (2004) 61:168-76. doi:10.1001/archpsyc.61.2.168

8. Bush G, Luu P, Posner MI. Cognitive and emotional influences in anterior cingulate cortex. Trends Cogn Sci (2000) 4:215-22. doi:10.1016/S1364-6613(00) 01483-2

9. Hou C, Lui J, Wang K, Li L, Liang M, He Z, et al. Brain responses to symptom provocation and trauma-related short-term memory recall in coal mining accident survivors with acute severe PTSD. Brain Res (2007) 1144:165-74. doi:10.1016/j.brainres.2007.01.089
10. Shin LM, Rauch SL, Pitman RK. Amygdala, medial prefrontal cortex, and hippocampal function in PTSD. Ann N Y Acad Sci (2006) 1071:69-79. doi:10.1196/annals.1364.007

11. Bremner JD, Staib LH, Kaloupek D, Southwick SM, Soufer R, Charney DS. Neural correlates of exposure to traumatic pictures and sound in Vietnam combat veterans with and without posttraumatic stress disorder: a positron emission tomography study. Biol Psychiatry (1999) 45:806-16. doi:10.1016/ S0006-3223(98)00297-2

12. Lanius RA, Frewen PA, Girotti M, Neufeld WJ, Stevens TK, Densmore M. Neural correlates to trauma script-imagery in posttraumatic stress disorder with and without comorbid major depression: a functional MRI investigation. Psychiatry Res (2007) 155:45-56. doi:10.1016/j.pscychresns.2006.11.006

13. Lanius RA, Bluhm R, Lanius U, Pain C. A review of neuroimaging studies in PTSD: heterogeneity of response to symptom provocation. J Psychiatr Res (2006) 40:709-29. doi:10.1016/j.jpsychires.2005.07.007

14. Radua J, Mataix-Cols D, Phillips ML, El-Hage W, Kronhaus DM, Cardoner $\mathrm{N}$, et al. A new meta-analytic method for neuroimaging studies that combines reported peak coordinates and statistical maps. Eur Psychiatry (2012) 27:605-11. doi:10.1016/j.eurpsy.2011.04.001

15. Radua J, Mataix-Cols D. Meta-analytic methods for neuroimaging data explained. Biol Mood Anxiety Disord (2012) 2:6. doi:10.1186/2045-5380-2-6

16. Dastjerdi M, Foster BL, Nasrullah S, Rauschecker AM, Dougherty RF, Townsend JD, et al. Differential electrophysiological response during rest, self-referential, and non-self-referential tasks in human posteromedial cortex. Proc Natl Acad Sci U S A (2011) 108:3023-8. doi:10.1073/pnas. 1017098108

17. Northoff G, Bermpohl F. Cortical midline structures and the self. Trends Cogn Sci (2004) 8:102-7. doi:10.1016/j.tics.2004.01.004

18. Northoff G, Heinzel A, deGreck M, Bermpohl F, Dobrowolny H, Panksepp J. Self-referential processing in our brain - a meta-analysis of imaging studies on the self. Neuroimage (2006) 31:440-57. doi:10.1016/j.neuroimage.2005.12.002

19. Svoboda E, McKinnon MC, Levine B. The functional neuroanatomy of autobiographical memory: a meta-analysis. Neuropsychologia (2006) 44:2189-208. doi:10.1016/j.neuropsychologia.2006.05.023

20. Summerfield JJ, Hassabis D, Maguire EA. Cortical midline involvement in autobiographical memory. Neuroimage (2009) 44:1188-200. doi:10.1016/j. neuroimage.2008.09.033

21. Qin P, Northoff G. How is our self related to midline regions and the defaultmode network? Neuroimage (2011) 57:1221-33. doi:10.1016/j.neuroimage. 2011.05.028

22. Robinson S, Keene CS, Iaccarino HF, Duan D, Bucci DJ. Involvement of retrosplenial cortex in forming associations between multisensory stimuli. Behav Neurosci (2011) 125:578-87. doi:10.1037/a0024262

23. Fletcher PC, Frith CD, Grasby PM, Shallice T, Frackowiak RS. Brain systems for encoding and retrieval of auditory-verbal memory. An in vivo study in humans. Brain (1995) 118:401-16. doi:10.1093/brain/118.2.401

24. Eger E, Henson RN, Driver J, Dolan RJ. Mechanisms of top-down facilitation in perception of visual objects studies by fMRI. Cereb Cortex (2007) 17:2123-33. doi:10.1093/cercor/bhl119

25. Ehring T, Ehlers A. Enhanced priming for trauma-related words predicts posttraumatic stress disorder. J Abnorm Psychol (2010) 120:234-9. doi:10.1037/ a0021080

26. Fischer H, Wik G, Fredrikson M. Functional neuroanatomy of robbery reexperience: affective memories studied with PET. Neuroreport (1996) 7:2081-6. doi:10.1097/00001756-199609020-00005

27. Osuch EA, Willis MW, Bluhm R. Neurophysiological responses to traumatic reminders in the acute aftermath of serious motor vehicle collisions using [15O]-H2O positron emission tomography. Biol Psychiatry (2008) 64:327-35. doi:10.1016/j.biopsych.2008.03.010

28. Hendler T, Rotshtein P, Yeshurun Y, Weizmann T, Kahn I, Ben-Bashat D, et al. Sensing the invisible: differential sensitivity of visual cortex and amygdala to traumatic context. Neuroimage (2003) 19:587-600. doi:10.1016/S10538119(03)00141-1

29. Shin LM, McNally RJ, Kosslyn SM, Thomson WL, Rauch SL, Alpert NM, et al. A positron emission tomographic study of symptom provocation in PTSD. Ann N Y Acad Sci (1997) 821:521-3. doi:10.1111/j.1749-6632.1997.tb48320.x

30. Yang P, Wu M-T, Hsu C-C, Ker J-H. Evidence of early neurobiological alternations in adolescents with posttraumatic stress disorder: a functional MRI study. Neurosci Lett (2004) 370:13-8. doi:10.1016/j.neulet.2004.07.033 
31. Morey RA, Petty CM, Cooper DA, LaBar KS, McCarthy G. Neural systems for executive and emotional processing are modulated by symptoms of posttraumatic stress disorder in Iraq war veterans. Psychiatry Res (2008) 162:59-72. doi:10.1016/j.pscychresns.2007.07.007

32. Elsesser K, Heuschen I, Pundt I, Sartory G. Attentional bias and evoked heartrate response in specific phobia. Cogn Emot (2006) 20:1092-107. doi:10.1080/ 02699930500375712

33. Elsesser K, Sartory G, Tackenberg A. Attention, heart rate and startle response during exposure to trauma-relevant pictures: a comparison of recent trauma victims and patients with posttraumatic stress disorder. J Abnorm Psychol (2004) 113:289-301. doi:10.1037/0021-843X.113.2.289

34. Elsesser K, Sartory G, Tackenberg A. Initial symptoms and reactions to traumarelated stimuli and the development of posttraumatic stress disorder. Depress Anxiety (2005) 21:61-70. doi:10.1002/da.20047

35. Oldfield RC. The assessment and analysis of handedness: the Edinburgh inventory. Neuropsychologica (1971) 9:97-113. doi:10.1016/0028-3932(71)90067-4

36. Lang PJ, Bradley MM, Cuthbert BN. International Affective Picture System (IAPS): Affective Ratings of Pictures and Instruction Manual. Technical report A-8. Gainesville, FL: University of Florida (2008).

37. Francati V, Vermetten E, Bremner JD. Functional neuroimaging studies in posttraumatic stress disorder: review of current methods and findings. Depress Anxiety (2007) 24:202-18. doi:10.1002/da.20208

38. Bryant RA, Harvey AG, Dang ST, Sackville T. Assessing acute stress disorder: psychometric properties of a structured clinical interview. Psychol Assess (1998) 10:215-20. doi:10.1037/1040-3590.10.3.215

39. Elsesser K. Interview zur Akuten Belastungsstörung; German version of Acute Stress Disorder Interview (ASDI). Unpublished manuscript, University of Wuppertal (1999).

40. DiNardo P, Brown TA, Barlow DH. Anxiety Disorders Interview Schedule for DSM-IV (ADIS-IV). San Antonio, TX: Psychological Corporation (1994).

41. Margraf J. Diagnostisches Inventar Psychischer Störungen (Mini-DIPS). Weinheim: Beltz-PVU (1994).

42. Horowitz M, Wilner N, Alvarez W. Impact of event scale: a measure of subjective stress. Psychosom Med (1979) 41:209-18.

43. Maercker A, Schützwohl M. Erfassung von psychischen belastungsfolgen: die impact of event skala - revidierte version (IES-R). Diagnostica (1998) 44:130-41.

44. Beck AT, Steer RA, Ball R, Ranieri W. Comparison of Beck Depression Inventories -IA and -II in psychiatric outpatients. J Pers Assess (1996) 67:588-97. doi:10.1207/s15327752jpa6703_13

45. Hautzinger M, Keller F, Kühner C. Beck Depressions-Inventar (BDI-II). Revision. Frankfurt/Main: Harcourt Test Services (2006).

46. Spielberger CD, Gorsuch RL, Lushene R, Vagg PR, Jacobs GA. Manual for the State-Trait Anxiety Inventory. Palo Alto, CA: Consulting Psychologists Press (1983).

47. Laux L, Glanzmann P, Spielberger CD. Das State-Trait-Angstinventar, Theoretische Grundlagen und Handanweisungen. Weinheim: Beltz (1981).

48. Hopper JW, Frewen PA, Sack M, Lanius RA, van der Kolk BA. The Responses to Script-Driven Imagery Scale (RSDI): assessment of state posttraumatic symptoms for psychobiological and treatment research. J Psychopathol Behav Assess (2007) 29:249-68. doi:10.1007/s10862-007-9046-0

49. Sack M. Der Einfluss Akuter Dissoziativer Symptome auf die Autonom-Vegetative Regulation, Habilitation Thesis. Hannover: Medizinische Hochschule Hannover (2005).

50. R Development Core Team. R: A Language and Environment for Statistical Computing. Vienna: R Foundation for Statistical Computing (2013).

51. Addis DR, McIntosh AR, Moscovitch M, Crawley AP, McAndrews MP. Characterizing spatial and temporal features of autobiographical memory retrieval networks: a parietal least squares approach. Neuroimage (2004) 23:1460-71. doi:10.1016/j.neuroimage.2004.08.007

52. Addis DR, Knapp K, Roberts RP, Schacter DL. Routes to the past: neural substrates of direct and generative autobiographical memory retrieval. Neuroimage (2012) 59:2908-22. doi:10.1016/j.neuroimage.2011.09.066

53. Dörfel D, Werner A, Schaefer M, von Kummer R, Karl A. Distinct brain networks in recognition memory share a defined region in the precuneus. Eur J Neurosci (2009) 30:1947-59. doi:10.1111/j.1460-9568.2009.06973.x

54. Freton M, Lemogne C, Bergouignan L, Delaveau P, Lehéricy S, Fossati P. The eye of the self: precuneus volume and visual perspective during autobiographical memory retrieval. Brain Struct Funct (2013). doi:10.1007/ s00429-013-0546-2

55. Lee TMC, Lee TMY, Raine A, Chan CCH. Lying about the valence of affective pictures: an fMRI study. PLoS One (2010) 5(8):e12291. doi:10.1371/journal. pone. 0012291

56. Sajonz B, Kahnt T, Margulies DS, Park SQ, Wittmann A, Stoy M, et al. Delineating self-referential processing from episodic memory retrieval: common and dissociable networks. Neuroimage (2010) 50:1606-17. doi:10.1016/j. neuroimage.2010.01.087

57. Spreng RN, Mar RA, Kim ASN. The common neural basis of autobiographical memory, prospection, navigation, theory of mind, and the default mode: a quantitative meta-analysis. J Cogn Neurosci (2009) 21:489-510. doi:10.1162/jocn.2008.21029

58. Levine B, Truner GR, Tisserand D, Hevenor SJ, Graham SJ, McIntosh AR. The functional neuroanatomy of episodic and semantic autobiographical remembering: a prospective functional MRI study. J Cogn Neurosci (2004) 16:1633-46. doi: $10.1162 / 0898929042568587$

59. Bluhm RL, Frewen PA, Coupland NC, Densmore M, Schore AN, Lanius RA. Neural correlates of self-reflection in post-traumatic stress disorder. Acta Psychiatr Scand (2012) 125:238-46. doi:10.1111/j.1600-0447.2011.01773.x

60. Cavanna AE, Trimble MR. The precuneus: a review of its functional anatomy and behavioral correlates. Brain (2006) 129:564-83. doi:10.1093/brain/awl004

61. Zhang S, Li C-SR. Functional connectivity mapping of the human precuneus by resting state fMRI. Neuroimage (2012) 59:3548-62. doi:10.1016/j.neuroimage. 2011.11.023

62. Cauda F, Geminiani G, D’Agata F, Sacco K, Duca S, Bagshaw AP, et al. Functional connectivity of the posteromedial cortex. PLoS One (2010) 5(9):e13107. doi:10.1371/journal.pone.0013107

63. Lanius RA, Bluhm RL, Coupland NJ, Hegadoren KM, Rowe B, Théberge J, et al. Default mode network connectivity as a predictor of post-traumatic stress disorder symptom severity in acutely traumatized subjects. Acta Psychiatr Scand (2010) 121:33-40. doi:10.1111/j.1600-0447.2009.01391.x

64. Daniels JK, McFarlane AC, Bluhm R, Moores KA, Clark R, Shaw ME, et al. Switching between executive and default mode network in posttraumatic stress disorder: alterations in functional connectivity. J Psychiatry Neurosci (2010) 35:258-66. doi:10.1503/jpn.090010

65. Daniels JK, Bluhm RL, Lanius RA. Intrinsic network abnormalities in posttraumatic stress disorder: research directions for the next decade. Psychol Trauma (2013) 5:142-8. doi:10.1037/a0026946

66. Elsesser K, Sartory G. Memory performance and dysfunctional cognitions in recent trauma victims and patients with posttraumatic stress disorder. Clin Psychol Psychother (2007) 14:464-74. doi:10.1002/cpp.545

67. Hanakawa T, Immisch I, Toma K, Dimyan MA, Van Gelderen P, Hallett M. Functional properties of brain areas associated with motor execution and imagery. J Neurophysiol (2003) 89:989-1002. doi:10.1152/jn.00132.2002

68. Guillot A, Di Rienzo F, MacIntyre T, Moran A, Collet C. Imagining is not doing but involves specific motor commands: a review of experimental data related to motor inhibition. Front Hum Neurosci (2012) 6:247. doi:10.3389/fnhum.2012.00247

69. Lotze M, Halsband U. Motor imagery. J Physiol (2006) 99:386-95. doi:10.1016/ j.jphysparis.2006.03.012

70. Hinds O, Thompson TW, Ghosh S, Yoo JJ, Whitfield-Gabrieli S, Triantafyllou C, et al. Roles of default-mode network and supplementary motor area in human vigilance performance: evidence from real-time fMRI. J Neurophysiol (2013) 109:1250-8. doi:10.1152/jn.00533.2011

71. Narayana S, Laird AR, Tandon N, Franklin C, Lancaster JL, Fox PT. Electrophysiological and functional connectivity of the human supplementary motor area. Neuroimage (2012) 62:250-65. doi:10.1016/j.neuroimage.2012.04. 060

72. Takada M, Hatanaka N, Tachibana Y, Miyachi S, Taira M, Inase M. Organization of prefrontal outflow toward frontal motor-related areas in macaque monkeys. Eur J Neurosci (2004) 19:3328-42. doi:10.1111/j.0953-816X.2004.03425.x

73. Nachev P, Kennard C, Husain M. Functional role of the supplementary and pre-supplementary motor areas. Nat Rev Neurosci (2008) 9:856-69. doi:10.1038/nrn2478

74. Chung GH, Han YM, Jeong SH, Jack CR. Functional heterogeneity of the supplementary motor area. Am J Neuroradiol (2005) 26:1819-23. Available from: http://www.ajnr.org/content/26/7/1819.long 
75. Clark CR, Egan GF, McFarlane AC, Morris P, Weber DL, Sonkilla C, et al. Updating working memory for words: a PET activation study. Hum Brain Mapp (2000) 9:42-54. doi:10.1002/(SICI)1097-0193(2000)9:1<42::AID-HBM5>3. $0 . \mathrm{CO} ; 2-6$

76. Clark CR, McFarlane AC, Morris P, Weber DL, Sonkkilla C, Shaw M, et al. Cerebral function in posttraumatic stress disorder during verbal working memory updating: a positron emission tomography study. Biol Psychiatry (2003) 53:474-81. doi:10.1016/S0006-3223(02)01505-6

77. Coull JT, Frith CD, Frackowiak RSJ, Grasby PM. A fronto-parietal network for rapid visual information processing: a PET study of sustained attention and working memory. Neuropsychologia (1996) 34:1085-95. doi:10.1016/00283932(96)00029-2

78. Lui Y, Gao J-H, Liotti M, Pu Y, Fox PT. Temporal dissociation of parallel processing in the human subcortical outputs. Nature (1999) 400:365-7.

79. Dinomais M, Ter-Minassian A, Tuilier T, Delion M, Wilke M, N'Guyen S, et al. Functional MRI comparison of passive and active movement: possible inhibitory role of supplementary motor area. Neuroreport (2009) 20:1351-5. doi:10.1097/WNR.0b013e328330cd43

80. D’Ostilio K, Collette F, Phillips C, Garraux G. Evidence for a role of a cortico-subcortical network for automatic and unconscious motor inhibition of manual responses. PLoS One (2012) 7(10):e48007. doi:10.1371/journal. pone. 0048007

81. Jaffard M, Longcamp M, Velay JL, Anton JL, Roth M, Nazarian B, et al. Proactive inhibitory control of movement assessed by event-related fMRI. Neuroimage (2008) 42:1196-206. doi:10.1016/j.neuroimage.2008.05.041

82. Simmonds DJ, Pekar JJ, Mostofsky SH. Meta-analysis of Go/No-go tasks demonstrating that $\mathrm{fMRI}$ activation associated with response inhibition is task-dependent. Neuropsychologia (2008) 46:224-32. doi:10.1016/j. neuropsychologia.2007.07.015

83. Pissiota A, Frans Ö, Fernandez M, von Knorring L, Fischer H, Fredrikson M. Neurofunctional correlates of posttraumatic stress disorder: a PET symptom provocation study. Eur Arch Psychiatry Clin Neurosci (2002) 252:68-75. doi:10.1007/s004060200014

84. Deiber MP, Passingham RE, Colebath JG, Friston KJ, Nixon PD, Frackowiack RSJ. Cortical areas and the selection of movement. A study with positron emission tomography. Exp Brain Res (1992) 84:393-402.

85. Humberstone M, Sawle GV, Clare S, Hykin J, Coxon R, Bowtell R, et al. Functional magnetic resonance imaging of single motor events reveals human presupplementary motor area. Ann Neurol (1997) 42:632-7. doi:10.1002/ana. 410420414

86. Isoda M, Hikosaka O. Switching from automatic to controlled action by monkey medial frontal cortex. Nat Neurosci (2007) 10:240-8. doi:10.1038/nn1830

87. Seitz RJ, Nickel J, Azari NP. Functional modularity of the medial prefrontal cortex: involvement in human empathy. Neuropsychology (2006) 6:743-51. doi:10.1037/0894-4105.20.6.743

88. Fusar-Poli P, Placentino A, Carletti F, Landi P, Allen P, Surguladze S, et al. Functional atlas of emotional faces processing: a voxel-based metaanalysis of 105 functional magnetic resonance imaging studies. J Psychiatry Neurosci (2009) 34:418-32. Available from: http://www.cma.ca/multimedia/ staticContent/HTML/N0/12/jpn/vol-34/issue-6/pdf/pg418.pdf

89. Driessen M, Beblo T, Mertens M, Piefke M, Rullkoetter N, Silva-Saavedra A, et al. Posttraumatic stress disorder and fMRI activation patterns of traumatic memory in patients with borderline personality disorder. Biol Psychiatry (2004) 55:603-11. doi:10.1016/j.biopsych.2003.08.018

90. Osuch EA, Benson B, Geraci M, Podell D, Herscovitch P, McCann UD, et al. Regional cerebral blood flow correlated with flashback intensity in patients with posttraumatic stress disorder. Biol Psychiatry (2001) 50:246-53. doi:10.1016/S0006-3223(01)01107-6

91. Vossel S, Weidner R, Fink GR. Dynamic coding of events within the inferior frontal gyrus in a probabilistic selective attention task. J Cogn Neurosci (2010) 23:414-24. doi:10.1162/jocn.2010.21441

92. Bledowski C, Kaiser J, Rahm B. Basic operations in working memory: contributions from functional imaging studies. Behav Brain Res (2010) 214:172-9. doi:10.1016/j.bbr.2010.05.041

93. Wager TD, Smith EE. Neuroimaging studies of working memory: a metaanalysis. Cogn Affect Behav Neurosci (2003) 3:255-74. doi:10.3758/CABN.3.4 255

94. Benuzzi F, Lui F, Duzzi D, Nichelli PF, Porro CA. Does it look painful or disgusting? Ask your parietal and cingulate cortex. J Neurosci (2008) 28:923-31. doi:10.1523/JNEUROSCI.4012-07.2008

95. Murphy FC, Nimmo-Smith I, Lawrence AD. Functional neuroanatomy of emotions: a meta-analysis. Cogn Affect Behav Neurosci (2003) 3:207-33. doi:10.3758/CABN.3.3.207

96. Beer JS, Hughes BL. Neural systems of social comparison and the above-average effect. Neuroimage (2010) 49:2671-9. doi:10.1016/j.neuroimage.2009.10.075

97. Cabanis M, Pyka M, Mehl S, Müller BW, Loos-Jankowiak S, Winterer G, et al. The precuneus and the insula in self-attributional processes. Cogn Affect Behav Neurosci (2013) 13:330-45. doi:10.3758/s13415-012-0143-5

98. Lamm C, Batson CD, Decety J. The neural substrate of human empathy: effects of perspective-taking and cognitive appraisal. J Cogn Neurosci (2007) 19:42-58. doi:10.1162/jocn.2007.19.1.42

99. Friston KJ, Holmes AP, Worsley KJ. How many subjects constitute a study? Neuroimage (1999) 10:1-5. doi:10.1006/nimg.1999.0439

100. Brewin CR, Andrews B, Valentine JD. Meta-analysis of risk factors for posttraumatic stress disorder in trauma-exposed adults. J Consult Clin Psychol (2000) 68:748-66. doi:10.1037/0022-006X.68.5.748

Conflict of Interest Statement: The authors declare that the research was conducted in the absence of any commercial or financial relationships that could be construed as a potential conflict of interest.

Received: 21 March 2014; accepted: 23 April 2014; published online: 08 May 2014. Citation: Cwik JC, Sartory G, Schürholt B, Knuppertz H and Seitz RJ (2014) Posterior midline activation during symptom provocation in acute stress disorder: an fMRI study. Front. Psychiatry 5:49. doi: 10.3389/fpsyt.2014.00049

This article was submitted to Neuropsychiatric Imaging and Stimulation, a section of the journal Frontiers in Psychiatry.

Copyright (C) 2014 Cwik, Sartory, Schürholt, Knuppertz and Seitz. This is an openaccess article distributed under the terms of the Creative Commons Attribution License (CC BY). The use, distribution or reproduction in other forums is permitted, provided the original author(s) or licensor are credited and that the original publication in this journal is cited, in accordance with accepted academic practice. No use, distribution or reproduction is permitted which does not comply with these terms. 